\title{
DIAGNÓSTICO DO USO DA TERRA NA REGIÃO CENTRO-OESTE DE MINAS GERAIS, BRASIL: A RENOVAÇÃO DA PAISAGEM PELA CANA-DE-AÇÚCAR E SEUS IMPACTOS SOCIOAMBIENTAIS.
}

\section{Diagnostic of the land use in the Midwest Region of Minas Gerais, Brazil: The renewal of the land- scape by the sugarcane crops and its social and enviromenmental impacts}

\author{
Edmar Geraldo Oliveira \\ Prof. no IFET Minas Gerais, Doutorando em Ciências Ambientais UFG \\ edmar@ifmg.edu.br \\ Manuel Eduardo Ferreira \\ Prof. Adjunto, Universidade Federal de Goiás UFG \\ manuel@iesa.ufg.br \\ Fernando Moreira de Araújo \\ Geográfo, Doutorando em Ciências Ambientais UFG \\ fernandomsbl@gmail.com
}

Artigo recebido em 08/12/2011 e aceito para publicação em 02/07/2012

RESUMO: Nos últimos anos, o Brasil tem experimentado um aumento significativo no consumo de etanol combustível, combinado com uma melhoria no preço internacional do açúcar. No período de 2000 a 2010, a área plantada com cana no país aumentou 97,59\% (equivalente a 4.526 .475 hectares). Estes fatos têm contribuído para uma transformação da dinâmica agrícola no bioma Cerrado (savana), apontando para uma competição entre culturas de cana-de-açúcar e outras com menor nível de investimento. Neste estudo avaliamos a expansão da cultura da cana de açúcar na região Centro-Oeste do Estado de Minas Gerais, especificamente em áreas de Cerrado, e seus impactos socioambientais para os municípios contidos na área de estudo, entre os anos de 1995 e 2010. Dentre os resultados principais, obtidos por meio de técnicas de sensoriamento remoto e geoprocessamento, indicaram uma expansão de $130 \%$ para o plantio de cana-de-açúcar, seguido por $87 \%$ e $31 \%$ de reflorestamento e outras culturas, respectivamente. Foi detectada ainda uma redução da ordem de 19,6\% da vegetação nativa, enquanto as áreas de pastagem perderam $8,5 \%$ da sua área original.

Palavras chaves: Mudanças no uso e cobertura da terra. Cana-de-açúcar. Cerrado. Sensoriamento Remoto.

ABSTRACT: In the last years, Brazil has experienced a significant increase in consumption of ethanol fuel, combined with an increase of sugarcane price in the international market. During the period 2000-2010 the area occupied by sugarcane increased $97.59 \%$ (equivalent to $4,526,475$ hectares). These facts have contributed for changings in the agriculture dynamic in the Cerrado biome (savanna), accentuating the substitution of less investment-demanding crops by sugarcane. In this study we have evaluated the expansion of sugarcane crops in the central and western part of Minas Gerais State, specifically in areas of Cerrado, as well as their socioeconomic and environmental impacts in the municipalities of the study area, during the 19952010 period. The main results, obtained with the support of remote sensing and GIS techniques, show an expansion of $130 \%$ in the areas planted with sugarcane, followed by $87 \%$ and $31 \%$ of reforestation and other crops, respectively. It was also detected a reduction of $19.6 \%$ in the native vegetation cover, while pasturelands faced a reduction of $8.5 \%$.

Key-words: Land use and land cover changes. Sugarcane. Cerrado. Remote Sensing. 


\section{INTRODUÇÃO}

O bioma Cerrado ocupa aproximadamente 204,7 milhões de hectares ou $24 \%$ do território brasileiro, fazendo-se presente em 10 estados da federação (área contínua), incluindo o Distrito Federal (IBGE, 2004). Desde a década de 1950, esse bioma - responsável por aproximadamente $5 \%$ da biodiversidade mundial (PIRES, 1999) - tem sido amplamente modificado pela ação antrópica, devido, principalmente, ao processo de interiorização da capital da República e das respectivas políticas de ocupação para a região central do país, incentivando o desenvolvimento da pecuária e da agricultura extensiva, como a soja, milho, algodão e, mais recentemente, da cana-de-açúcar.

Tais mudanças apoiaram-se, sobretudo, na implantação de novas infraestruturas viárias e energéticas, bem como na modernização da agricultura, permitindo o pioneirismo de atividades agrárias rentáveis, em detrimento de uma biodiversidade até então pouco conhecida e alterada. Outro aspecto que favoreceu a expansão da agricultura no Cerrado foi a sua topografia bastante plana, excelente para a mecanização de extensas áreas, especialmente no Triângulo Mineiro e na região sul de Goiás (FERREIRA et al., 2009; FERREIRA et al., 2012). Com relação ao uso da terra neste bioma, as duas classes mais representativas são as pastagens cultivadas e as culturas agrícolas, que ocupam cerca de 54 e 21,5 milhões de hectares, respectivamente, sendo que ambas apresentam distribuição espacial bastante heterogêneas (SANO et al., 2008).

Em virtude do aumento da demanda pelo açúcar e etanol combustível, a área de plantio da cana-de-açúcar continua se expandindo no Brasil, com frequente aumento de produtividade. $\mathrm{O}$ cenário econômico atual indica um mercado favorável, estimulando a expansão das áreas plantadas. A saturação de áreas cultivadas com cana-de-açúcar no Estado de São Paulo (maior produtor nacional), aliada à moderna tecnologia de maquinários e insumos agrícolas, pode ser apontado como um dos fatores determinantes para a expansão dessa produção para outros Estados.

$\mathrm{O}$ aumento da área plantada de cana-de-açúcar vem ocorrendo rumo ao centro do país, concentrando-se em dois grandes e representativos estados do Cerrado: Goiás e Minas Gerais (CASTRO et al., 2010). Tal tendência se deve, principalmente, às extensas faixas de terras, boa infraestrutura viária $\mathrm{e}$ proximidade de mercados consumidores, propiciando uma nova dinâmica no uso e ocupação do solo nesse bioma. Como o plantio da cana requer um maior nível de investimento, ela tende a ocupar as melhores terras, sejam elas áreas remanescentes de Cerrado, agricultura ou pecuária. Pesquisas recentes realizadas para Goiás demonstram que apenas $12 \%$ dessa expansão ocorreu em áreas de pecuária, contradizendo o discurso oficial, pelo menos até o momento, de que as áreas prioritárias a serem incorporadas proviriam das pastagens degradadas (CASTRO et al., 2007; MIZIARA, 2009; SILVA e MIZIARA, 2011).

No caso de Minas Gerais, entre os anos de 2005 e 2006, ocorreu o maior crescimento entre aqueles produtores de cana-de-açúcar (26,9\%), alcançando a condição de segundo maior produtor nacional na safra 2009/2010 (concentrado nas regiões do Triângulo Mineiro/Alto Paranaíba, Noroeste e Centro-Oeste do Estado).

Nesse contexto se insere o presente estudo, tendo como objetivo a análise temporal da conversão e uso do solo na região Centro-Oeste de Minas Gerais, entre os anos de 1995 e 2010, por meio da utilização de técnicas de sensoriamento remoto e geoprocessamento. Dentre os objetivos específicos, o estudo visa identificar o nível de competição estabelecido entre a cultura de cana-de-açúcar e as demais áreas de cultivos, bem como mapear os remanescentes de Cerrado para a área em questão. Nossa hipótese é a de que a referida expansão na região Centro-Oeste de Minas Gerais vem ocorrendo sobre áreas de pastagens cultivadas e agricultura, configurando-se numa nova etapa da fronteira agrícola.

\section{MATERIAIS E MÉTODOS}

\section{Caracterização da área de estudo}

A região Centro-Oeste do Estado de Minas Gerais é constituída por 56 municípios que, juntos, abrangem um território de $31.543 \mathrm{~km}^{2}$. Entre 2000 e 2010, a região apresentou a segunda maior taxa de crescimento populacional do estado, de $1,27 \%$ ao ano, atingindo 1,12 milhão de habitantes em 2010, 
equivalente a $5,7 \%$ do total de Minas Gerais (IBGE, 2010). É uma região com índice de desenvolvimento humano (IDH) médio de 0,788 (PNUD, 2000), com uma economia diversificada, destacando os municípios de Itaúna, Formiga e Divinópolis, além de outros de importância regional como Arcos, Oliveira, Campo Belo, Nova Serrana e Piumhi.

Os municípios do Centro-Oeste mineiro que compõem este estudo são aqueles com área plantada e produção de cana-de-açúcar com relevância em escala industrial. Para subsidiar a escolha dos municípios, foi feito um levantamento criterioso junto ao banco de dados agregados do IBGE/SIDRA (produção agrícola municipal) e no CANASAT/INPE, com objetivo de analisar a variação da área plantada e produção no período de 2002 a 2010. Os dados obtidos indicaram que nesta região de Minas Gerais, os municípios com maior área plantada e produção eram Arcos, Bambuí, Iguatama, Japaraíba, Lagoa da Prata, Luz e Pompéu, os quais compõem a área de estudo desta pesquisa (Figura 1).

Figura 1. Localização da área de estudo, com destaque para os municípios de Arcos, Bambuí, Iguatama, Lagoa da Prata, Luz, Japaraíba e Pompéu.

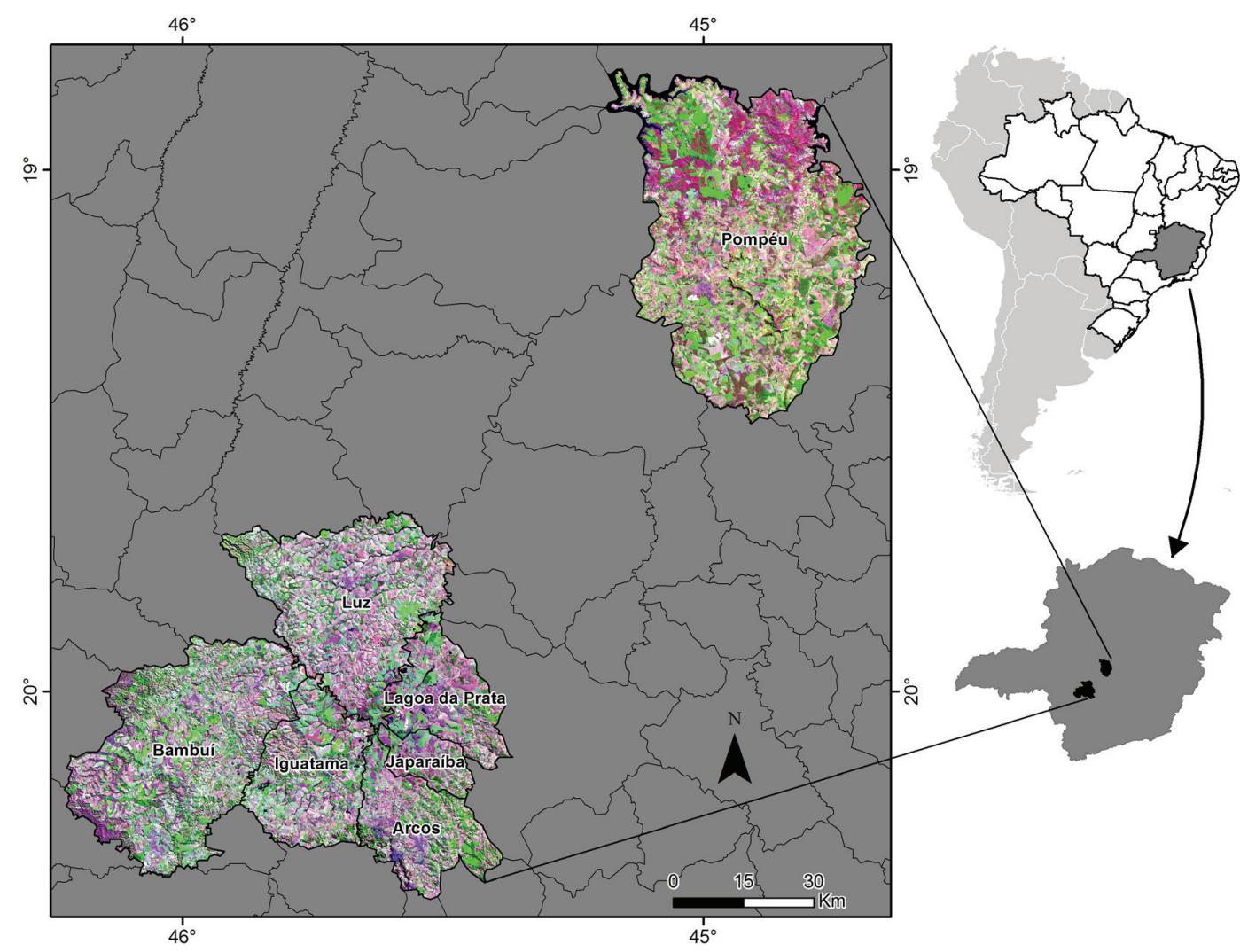

Org. dos autores.

\section{Processamento das Imagens de Satélite}

O sensoriamento remoto é uma ferramenta de grande utilidade para o monitoramento agrícola, principalmente por permitir o acompanhamento da cultura ao longo do tempo, a determinação da área plantada, demarcação de novas áreas de cultivo, entre outras possibilidades. Apresenta ainda a vantagem de recobrir extensas áreas com custos reduzidos, podendo os dados serem armazenados para usos posteriores, para fins de comparação na gestão dos recursos naturais. Por outro lado, e especificamente para a cana-de-açúcar, esta possui características foliares que facilitam a sua identificação nas imagens de 
Diagnóstico do uso da terra na região Centro-Oeste de Minas Gerais, Brasil: a renovação da paisagem pela cana-de-açúcar e seus impactos socioambientais. Edmar Geraldo Oliveira, Manuel Eduardo Ferreira, Fernando Moreira de Araújo

satélites, inclusive por ser uma cultura semi-perene, plantada em grandes extensões de terra (RUDORFF e SUGAWARA, 2007).

As imagens de satélites utilizadas neste estudo foram as do sensor Landsat 5-TM, obtidas no portal de dados do Instituto Nacional de Pesquisas Espaciais - INPE (www.inpe.br), de modo a representar quatro recortes temporais: 1995, 2000, 2005 e 2010. O início desta série histórica foi escolhido por ocasião da retomada de investimentos nas lavouras canavieiras, em especial na região Centro-Sul do país. Optou-se aqui por utilizar imagens registradas nos meses de junho e julho, período em que a interferência de nuvens é significativamente menor na área de estudo.

O mapeamento das classes de uso da terra (agricultura, cana-de-açúcar, mineração, pastagem cultivada, perímetro urbano, reflorestamento e vegetação remanescente - Cerrado) foi realizado com o método de classificação supervisionada por Máxima
Verossimilhança (MAXVER), seguido por interpretação visual. Este método utiliza parâmetros estatísticos (distribuição normal gaussiana) para a ponderação das distâncias entre as amostras de pixels (média dos valores de níveis de cinza), visando agrupá-los em diferentes classes de uso do solo; quanto maior a quantidade de amostras (fase de treinamento do algoritmo), maior será a acurácia da classificação (INPE, 2009; MOREIRA, 2011).

Foram necessárias três órbitas/pontos do Landsat-TM para cobrir toda a área de estudo: 218/73, 219/73 e 219/74. Ao todo, foram utilizadas doze imagens, conforme exposto na Tabela 1. Após a aquisição gratuita das imagens, os procedimentos realizados foram o georreferenciamento (com base em parâmetros obtidos de imagens do projeto Geocover) e a geração de mosaico para cada conjunto de dados, possibilitando ao fim o recorte e análise da área de estudo.

Tabela 1. Cenas Landsat-TM utilizadas no mapeamento do uso da terra para a região

Centro-Oeste de Minas Gerais.

\begin{tabular}{l|c|c|c}
\hline \multicolumn{2}{c}{ Ano Órbita/ponto } & \multicolumn{2}{c}{ Datas } \\
\hline 1995 & & $12 / 06 / 2011$ & \\
2000 & \multirow{2}{*}{$218 / 73,219 / 73$ e $219 / 74$} & $25 / 06 / 2000$ & \multirow{2}{*}{ Bandas $\mathrm{R}(5) / \mathrm{G}(4) / \mathrm{B}(3)$} \\
2005 & & $09 / 07 / 2005$ & \\
\hline 2010 & & $21 / 06 / 2010$ & \\
& &
\end{tabular}

Org. dos autores.

Outras bases de dados utilizadas nesta pesquisa foram os mapas políticos do IBGE, com limites de municípios e regiões (http://mapas.ibge.gov.br/), os mapas temporais de plantios da cana-de-açúcar do projeto CANASAT/INPE (http://www.dsr.inpe.br/laf/ canasat/) e as séries históricas da Produção Agrícola Municipal 2010 do IBGE/SIDRA (http://www.sidra. ibge.gov.br/), importantes para a definição da área de estudo e aferição dos resultados.

\section{RESULTADOS E DISCUSSÕES}

\section{A expansão do setor sucroalcooleiro no Cerrado}

Nos últimos anos, tem-se intensificada a busca por fontes alternativas de energia, de forma a mini- mizar a pressão sobre o uso de combustíveis fósseis, principalmente devido aos indícios científicos quanto ao processo de mudanças climáticas e do esgotamento, em médio prazo, do modelo energético predominante (RIBEIRO et al., 2009). No entanto, para Silveira e Carvalho (2008), existe um discurso muito forte, às vezes em tom exagerado, o qual afirma que os biocombustíveis são fontes limpas de energia, capazes de diminuir, em grandes escalas, os anunciados riscos ambientais decorrentes deste modelo.

Nesta perspectiva, a utilização do etanol como combustível automotivo tem sido celebrada como importante alternativa à gasolina e ao diesel, cujas fontes de recursos são finitas, e os níveis de emissões de $\mathrm{CO}_{2}$ mais elevados. Somado a isto, as vantagens econômicas e ambientais do etanol brasileiro, produzi- 
do a partir da cana-de-açúcar, frente àquele produzido a partir de outras matérias primas como o milho, a beterraba e o trigo (todos com menor eficiência energética), fizeram com que o país despontasse como o líder mundial neste setor. A produção de veículos flex - etanol e gasolina (iniciada em 2003) já representa mais de $90 \%$ do total de veículos licenciados no Brasil (SOUZA e MACEDO, 2009).

Por outro lado, tal aumento no consumo do etanol, associado a uma valorização no preço do açúcar no mercado internacional, tem estimulado vigorosos investimentos no setor sucroalcooleiro. Segundo levantamento da União da Indústria Canavieira (UNICA), entre 2000 e 2008, a produção de cana cresceu $10,3 \%$ ao ano. O Brasil é atualmente o maior produtor de cana de açúcar no mundo, com $33 \%$ das áreas de plantio (SANT'ANNA et al., 2009), 20\% da produção e 50\% das exportações de açúcar (UNICA, 2011). Para atender essa demanda, a área plantada de cana no Brasil aumentou em 97,59\% no período de 1995 a 2010, o equivalente à área de 4.526 .475 ha (IBGE/SIDRA, 2011).

Em Minas Gerais, foco deste estudo, a expansão das lavouras de cana tem ocorrido sobre as regiões do Triângulo Mineiro, Noroeste e Centro-Oeste do Estado; de acordo com dados do IBGE/SIDRA, enquanto o crescimento médio da área plantada para o período de 2002 a 2010 foi de 168,56\%, no Triângulo Mineiro esta expansão foi de $315,08 \%$. Na mesorregião Oeste de Minas, o aumento foi da ordem de 280,86\%, e na mesorregião Noroeste do estado, o incremento na área plantada foi de $150,09 \%$ (Tabela 2).

Tabela 2. Evolução da área plantada (em hectares) de cana-de-açúcar nas 12 mesorregiões geográficas (IBGE) que compõem o Estado de Minas Gerais, no período de 2002-2010.

\begin{tabular}{l|l|l|l|l|l|l|l|ll}
\hline & $\mathbf{2 0 0 2}$ & $\mathbf{2 0 0 3}$ & $\mathbf{2 0 0 4}$ & $\mathbf{2 0 0 5}$ & $\mathbf{2 0 0 6}$ & $\mathbf{2 0 0 7}$ & $\mathbf{2 0 0 8}$ & $\mathbf{2 0 0 9}$ & $\mathbf{2 0 1 0}$ \\
\hline Estado de Minas Gerais (Total) & $\mathbf{2 7 7 . 9 7 7}$ & $\mathbf{3 0 3 . 0 4 3}$ & $\mathbf{3 3 4 . 6 6 8}$ & $\mathbf{3 4 9 . 1 1 2}$ & $\mathbf{4 3 1 . 3 3 8}$ & $\mathbf{4 9 6 . 9 3 3}$ & $\mathbf{6 1 0 . 4 5 6}$ & $\mathbf{7 1 5 . 6 2 8}$ & $\mathbf{7 4 6 . 5 2 7}$ \\
\hline Triângulo Mineiro/Alto Paranaíba & 118.636 & 141.798 & 165.352 & 176.791 & 251.920 & 290.237 & 381.804 & 467.258 & 492.440 \\
\hline Oeste de Minas & 5.643 & 5.743 & 5.530 & 5.293 & 5.990 & 14.321 & 20.652 & 26.681 & 21.492 \\
\hline Noroeste de Minas & 9.830 & 9.880 & 8.770 & 10.865 & 12.305 & 18.315 & 19.010 & 22.500 & 24.584 \\
\hline Central Mineira & 23.677 & 25.176 & 27.885 & 27.815 & 28.862 & 31.280 & 34.128 & 42.177 & 42.123 \\
\hline Vale do Mucuri & 6.391 & 6.926 & 6.480 & 6.875 & 9.058 & 9.523 & 11.219 & 11.199 & 10.799 \\
\hline Sul/Sudoeste de Minas & 32.969 & 32.184 & 37.019 & 39.219 & 40.304 & 42.241 & 49.446 & 50.939 & 61.129 \\
\hline Norte de Minas & 23.914 & 25.225 & 25.888 & 25.086 & 24.356 & 30.738 & 30.451 & 31.075 & 31.283 \\
\hline Jequitinhonha & 7.540 & 7.435 & 7.498 & 8.247 & 8.360 & 8.774 & 8.874 & 9.137 & 8.477 \\
\hline Campo das Vertentes & 2.295 & 2.479 & 1.736 & 1.695 & 1.659 & 2.514 & 2.720 & 2.769 & 2.744 \\
\hline Vale do Rio Doce & 10.462 & 10.385 & 11.755 & 10.890 & 11.074 & 10.870 & 11.648 & 11.727 & 11.734 \\
\hline Zona da Mata & 25.590 & 26.098 & 26.900 & 26.759 & 27.328 & 27.399 & 29.551 & 28.388 & 28.107 \\
\hline Região Metropolitana - Belo Horizonte & 11.030 & 9.714 & 9.855 & 9.577 & 10.122 & 10.721 & 10.953 & 11.778 & 11.615 \\
\hline
\end{tabular}

Fonte: IBGE - Produção Agrícola Municipal. Disponível em www.sidra.ibge.gov.br - Acesso em 15/11/2011

Os dados apresentados neste trabalho vão ao encontro das constatações de Miziara (2006), ao desenvolver estudos sobre a expansão da fronteira agrícola no Cerrado, ressaltando os fatores determinantes na escolha de novas áreas para o cultivo da cana, condicionada pela fertilidade do solo, topografia e infraestrutura, especialmente a rodoviária.

Tais fatores são facilmente verificados no caso da mesorregião Triângulo Mineiro/Alto Paranaíba, a principal produtora de cana-de-açúcar no estado de Minas Gerais. Trata-se de uma região com solos com boa fertilidade, condições topográficas favoráveis, boa infraestrutura viária e proximidade com São Paulo (reduzindo os custos de escoamento da produção). Por sua vez, as regiões oeste e noroeste também apresentam malha viária satisfatória, topografia propícia e preços de terra mais acessíveis em relação ao Triângulo Mineiro e ao Estado de São Paulo. Estudo desenvolvido por Carrijo (2008) apontou na mesma direção, ao analisar a expansão do setor sucroalcooleiro no estado de Goiás, constatando que as empresas deste ramo consideram a existência de vantagens competitivas como, por exemplo, os preços das terras e dos arrendamentos no Centro-Oeste (mais baixos em 
Diagnóstico do uso da terra na região Centro-Oeste de Minas Gerais, Brasil: a renovação da paisagem pela cana-de-açúcar e seus impactos socioambientais. Edmar Geraldo Oliveira, Manuel Eduardo Ferreira, Fernando Moreira de Araújo

relação às regiões Sul e Sudeste), uma topografia plana que facilita a mecanização do plantio e da colheita, as condições favoráveis do solo e do clima, além da disponibilidade de recursos hídricos.

A Tabela 3 apresenta os resultados deste estudo para a variação de uso e ocupação do solo nos municípios de Arcos, Bambuí, Iguatama, Japaraíba, Lagoa da Prata, Luz e Pompéu, no período de 1995 a 2010. As principais mudanças no uso do solo ocor- reram em função da expansão em $130,46 \%$ da área plantada de cana-de-açúcar, $87,07 \%$ de reflorestamento e $31,55 \%$ de culturas agrícolas. As variações de perda ficaram por conta da redução em $19,6 \%$ das áreas remanescentes de Cerrado, além de $8,48 \%$ das pastagens cultivadas.

Tabela 3. Conversão do uso e ocupação do solo (em hectares) nos municípios do Centro-Oeste de Minas Gerais, no período $1995-2010$.

\begin{tabular}{l|l|l|l|l|l|l|l}
\hline Municípios & $\begin{array}{l}\text { Cana-de- } \\
\text { açúcar }\end{array}$ & Agricultura & $\begin{array}{l}\text { Pastagem } \\
\text { Cultivada }\end{array}$ & Reflorestamento & Remanescente & $\begin{array}{l}\text { Corpo } \\
\text { hídrico }\end{array}$ & $\begin{array}{l}\text { Perímetro } \\
\text { urbano }\end{array}$ \\
\hline Arcos & 1.695 & 1.191 & -2.794 & 938 & -2.433 & -3 & 373 \\
\hline Bambuí & 10.322 & -211 & -4.304 & 7.878 & -13.943 & 39 & 245 \\
\hline Iguatama & 3.210 & 4.584 & -2.830 & 813 & -5.884 & 37 & 65 \\
\hline Japaraíba & 220 & 369 & -71 & 151 & -756 & 0 & 38 \\
\hline Lagoa da Prata & 4.718 & -522 & -3.177 & 564 & -1.754 & -32 & 203 \\
\hline Luz & 9.048 & 6.665 & -11.570 & 1.068 & -5.339 & -1 & 132 \\
\hline Pompéu & 12.439 & 1.627 & -2.167 & 13.212 & -30.676 & 924 & 307 \\
\hline Total & 41.652 & 13.703 & -22.580 & 24.623 & -60.783 & 964 & 1.364 \\
\hline
\end{tabular}

Fonte: Dados obtidos por imagens de satélite (Landsat 5-TM, resolução espacial de 30 metros).

Para atender a esta crescente demanda de álcool e açúcar, grandes investimentos estão sendo feitos no setor sucroalcooleiro, com a implantação de novas usinas e arrendamentos rurais. $\mathrm{O}$ vigor demonstrado pelo setor encontra espaço na medida em que existe grande quantidade de terras aptas ao cultivo da cana-de-açúcar. De acordo com o zoneamento agroecológico da cana-de-açúcar, publicado por meio do Decreto n ${ }^{\circ} 6.961$ de 17 de setembro de 2009, o país possui cerca de 64,7 milhões de hectares que poderão ser cultivados com cana. As terras que estão sendo incorporadas à expansão do agronegócio canavieiro são aquelas dotadas de uma combinação convergente de vários fatores que potencializem a renda fundiária. Ou seja, a expansão tem se destinado para as áreas já inseridas na dinâmica econômica nacional, com $85 \%$ das lavouras de cana-de-açúcar concentradas na região Centro-Sul (SOUZA, 2008, p. 13).

Carrijo e Miziara (2009), durante estudo de caso realizado em Goiás, apontaram na mesma direção, ao verificar que o crescimento da produção da cana-de-açúcar está ocorrendo de forma diferente daquela divulgada para a sociedade (i.e. plantios em áreas de pastagens "degradadas" e áreas marginalizadas, como as semiáridas). Em pesquisas realizadas junto à Secretaria de Indústria e Comércio do Estado de Goiás (análise dos projetos aprovados pelo PRODUZIR), assim como na pesquisa de campo realizada no município de Mineiros, verifica-se que a atividade canavieira está procurando os melhores solos goianos, os quais, consequentemente, já possuem alguma atividade produtiva.

Nos municípios da região Centro-Oeste de Minas, destacados para este estudo, os dados indicam que a expansão da área plantada de cana-de-açúcar ocorreu predominantemente sobre as áreas de pastagens $(48,75 \%)$, agricultura $(33,84 \%)$ e remanescentes $(14,18 \%)$ (Figura 2A). Ao analisar o aumento da área plantada em cada município, percebe-se que na maioria deles (cinco) o avanço foi sobre as pastagens; já em Bambuí e Iguatama o setor que mais cedeu espaço para as lavouras de cana foi o da cultura agrícola. Estes dados confirmam a hipótese inicial deste trabalho, de que a expansão da cana na região oeste de Minas vem ocorrendo sobre áreas de pastagens cultivadas e culturas agrícolas. Entre 1995 e 2010, no município de Pompéu, 5.732 ha de áreas remanescentes de Cerrado foram convertidos para lavouras de cana-de-açúcar (Figura 2B). 
Figura 2. Classes de uso da terra convertidas em cana-de-açúcar nos principais municípios produtores da região Centro-Oeste de Minas Gerais, no período de 1995 a 2010.
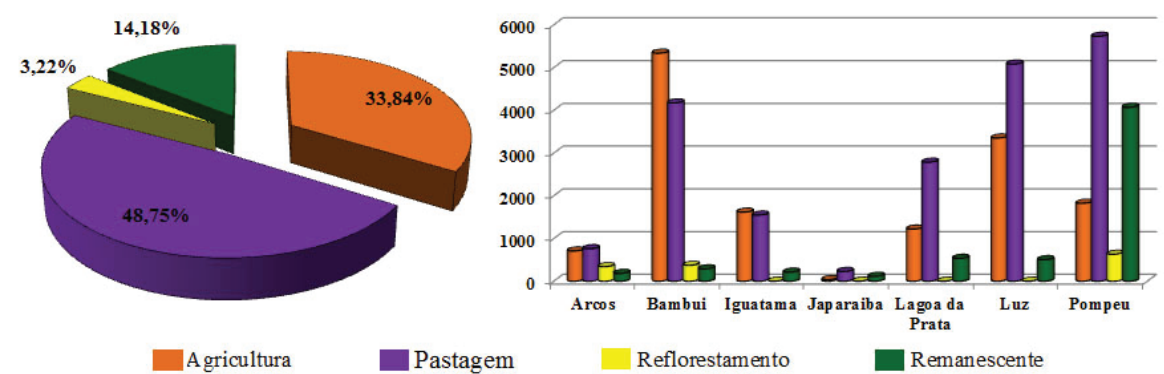

Fonte: Imagens de satélite (Landsat 5-TM). Org. dos autores.

Os resultados deste estudo estão em concordância com a tese de que a cana-de-açúcar tende a ocupar os melhores solos em razão de possuir um maior nível de investimento (SOUZA, 2008; CARRIJO e MIZIARA 2009). Ao comparar, por exemplo, o nível de investimento da soja e da cana-de-açúcar, esta última apresenta uma aplicação de recursos 2,5 vezes maior em relação à primeira (MIZIARA, 2009). A mudança no padrão tecnológico também reflete diretamente no nível de investimentos, os quais resultam na transformação da base agrícola, com efeitos sobre uma nova etapa da expansão da fronteira agrícola, fato constatado em Goiás (MIZIARA, 2006; SILVA e MIZIARA, 2011).

No período analisado neste estudo (1995 2010), a cana-de-açúcar expandiu nos municípios pesquisados da região Centro-Oeste de Minas, em todos os recortes temporais. Entretanto, o maior crescimento de área plantada ocorreu entre os anos de 2005 a 2010. Neste intervalo, o avanço das lavouras foi de $55,61 \%$, frente aos $25,89 \%$ observados entre 1995 e 2000 e os $17,64 \%$ ocorridos entre os anos 2000 e 2005 (Figura 3).

Figura 3. Mapa de uso e ocupação do solo da região Centro-Oeste de Minas Gerais, para os anos de 1995, 2000, 2005 e 2010.

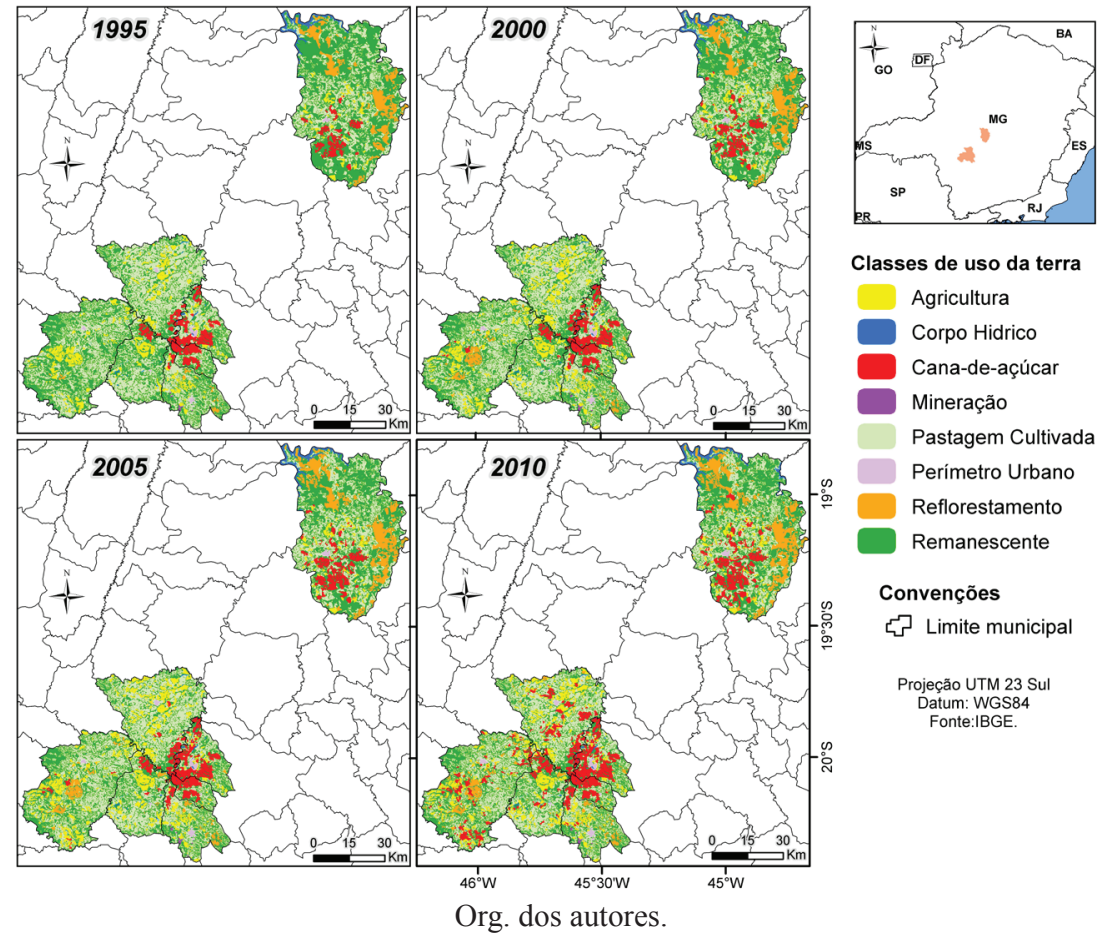


Diagnóstico do uso da terra na região Centro-Oeste de Minas Gerais, Brasil: a renovação da paisagem pela cana-de-açúcar e seus impactos socioambientais. Edmar Geraldo Oliveira, Manuel Eduardo Ferreira, Fernando Moreira de Araújo

Entre os municípios estudados, a maior expansão da cana ocorreu em Bambuí; nas imagens de 1995, a área deste cultivo era praticamente desprezível naquele município (figura 3). O crescimento da área plantada entre o primeiro e o segundo intervalo foi ainda restrito (em 2005 a área cultivada era de 1.308 ha). Contudo, foi no período de 2005 a 2010 que se registrou uma expansão mais intensiva, ocasião em que a área plantada chegou a 10.322 ha; ou seja, um crescimento de quase sete vezes. Esta expressiva mudança coincidiu com a instalação no município de Bambuí de uma usina de grande porte para a produção de etanol.

Tais dados apresentados corroboram com a tese da transformação da dinâmica agrícola e apontam para uma competição entre a cana de açúcar e outras culturas com menor nível de investimento. Neste caso, a expansão da cana ocorreu majoritariamente sobre áreas de pastagens cultivadas e cultivos de grãos.

\section{Impactos socioambientais}

Sob o ponto de vista econômico, o setor sucroalcooleiro no Brasil tem grande importância, com reflexo no Produto Interno Bruto (PIB) setorial de US\$ 28 bilhões ou 1,5\% do PIB nacional para 2008 (ROVERE et al., 2009). Estudo sobre os efeitos sócio-econômicos da expansão da cana-de-açúcar no Vale do São Patrício - GO demonstram que o PIB per capita dos municípios com usina receberam, no período de 2001 a 2006, um aumento muito acima daqueles que não possuem usina (ÁVILA, 2009). Ao desenvolver o presente trabalho, buscou-se também fazer uma análise da relação entre a expansão canavieira e a variação do PIB per capita.
Os dados indicaram que a expansão da cana-de-açúcar no Centro-Oeste mineiro tem contribuído para o crescimento econômico dos municípios de Arcos, Bambuí, Iguatama, Lagoa da Prata, Luz, Japaraíba e Pompéu, o que se confirma pelo aumento do PIB per capita destas localidades, acima da média regional e estadual. Ressalva-se que, no período analisado, além do crescimento das lavouras de cana, constatou-se também o crescimento das áreas de agricultura e de reflorestamento, o que, entre outros fatores, pode ter contribuído para este fato. Os dados mencionados referem-se ao intervalo entre 1999 e 2008, de modo a permitir uma comparação dos efeitos da expansão da cana nestes municípios. Neste período, a média do PIB per capita dos municípios supracitados cresceu 224,69\%, enquanto o crescimento do PIB da região Centro-Oeste de Minas Gerais foi de 179,2\%, contra $182,06 \%$ no estado.

A expansão da cana nessa região (Centro-Oeste de Minas) intensificou-se a partir de 2006, fenômeno que contribuiu para um maior crescimento do PIB per capita dos municípios que integram este estudo. Entre 2006 e 2008, a média do crescimento do PIB nos municípios que compõem a área de estudo foi de 39,94\%, enquanto que na região Centro-Oeste de Minas Gerais foi de 22,49\%, contra $29,1 \%$ no estado. Esta curva de crescimento fez com que em 2008 o PIB per capita dos municípios que tiveram a expansão da cana-de-açúcar crescesse de forma mais contundente e alcançasse o PIB per capita do Estado (figura 4A). Entre 1999 e 2008, todos os municípios estudados apresentaram crescimento do PIB per capita acima de $150 \%$, com destaque para o município de Iguatama, que teve uma variação positiva de 339\% (figura 4B).

Figura 4. Variação do PIB per capita no período de 1999 a 2008.

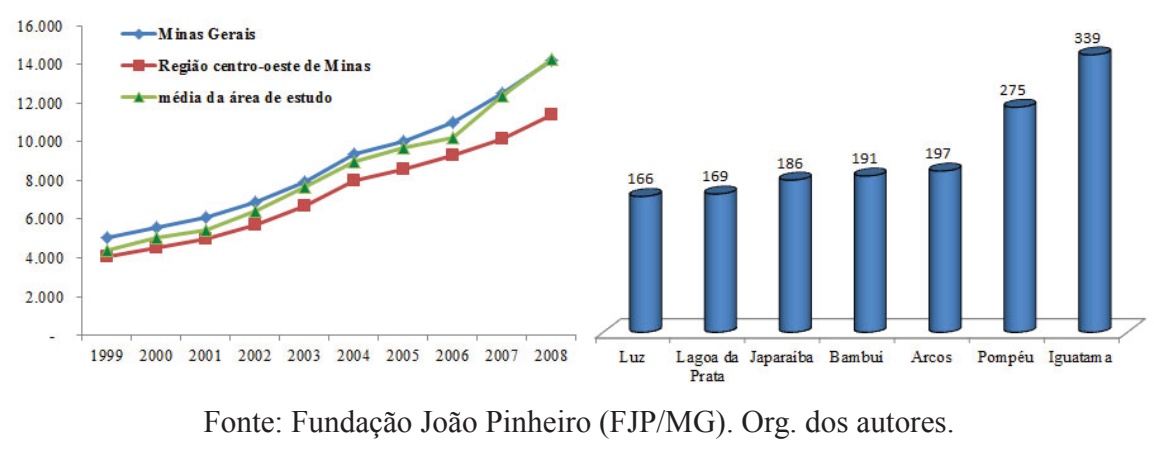

Soc. \& Nat., Uberlândia, ano 24 n. 3, 545-556, set/dez. 2012 
Se por um lado a economia é estimulada pelo setor sucroalcooleiro, o aumento expressivo das áreas cultivadas com cana-de-açúcar no Cerrado tem despertado diversas preocupações em relação aos impactos ambientais. Há fortes evidências de que o avanço do setor sucroalcooleiro tem prejudicado a manutenção das áreas remanescentes de Cerrado, como observado na mesorregião Sul Goiana, com elevada fragmentação, sobretudo em áreas de reserva legal e de preservação permanente (matas ciliares) (FERREIRA et al., 2009). Para Rovere et al. (2009), os pontos críticos do setor estão relacionados à alteração da biodiversidade, perda de solos, disponibilidade hídrica, qualidade do ar, clima global, segurança alimentar e condições de trabalho.

Os resultados do quarto relatório de avaliação das mudanças climáticas globais, divulgados em 2007 pelo Painel Intergovernamental sobre Mudanças do Clima (IPCC), alertaram para a possibilidade de aumento da temperatura global nas próximas décadas em até $5{ }^{\circ} \mathrm{C}$, seguido pela alta possibilidade de redução ou variação no ciclo de chuvas, ambas as previsões aplicáveis ao bioma Cerrado e Amazônia. O relatório destacou ainda que a maior parte do acréscimo de temperatura observado nos últimos 50 anos foi provocada pelo aumento na emissão de gases do efeito estufa, provenientes de atividades humanas, especialmente devido à queima de combustível fóssil e mudanças no uso da terra.

De acordo com Gibbs et al. (2008), dentre os cultivares utilizados para a produção de etanol, a cana-de-açúcar é a que apresenta o melhor custo-benefício, tanto em termos de eficiência energética quanto na emissão de gases de efeito estufa (gerados durante o plantio, ao substituir a cobertura vegetal nativa por uma cultura não-perene); ainda assim, este estudo aponta para o fato de que centenas de anos seriam necessários para que o uso dos biocombustíveis fossem compensatórios para o débito de carbono na atmosfera, uma vez que o desmatamento e as queimadas associados a estes plantios emitem uma grande quantidade de dióxido de carbono. Resultados semelhantes foram observados por Borges et al. (2011), contabilizando a emissão de $\mathrm{CO}_{2}$ a partir das queimadas associadas a estes plantios em Goiás.

Com relação à mudança de temperatura na área agrícola, SCOTT et al. (2011) apontaram uma pequena diminuição da temperatura no clima local em áreas cultivadas com cana-de-açúcar, quando comparadas com áreas de pastagens; neste estudo foram utilizadas informações do Instituto Nacional de Pesquisas Espaciais (INPE) e do Laboratório de Processamento de Imagens e Geoprocessamento (LAPIG) da Universidade Federal de Goiás (UFG), para avaliar o impacto no clima local da expansão da cana-de-açúcar no cerrado brasileiro. Os resultados indicam que a cana pode até ajudar a resfriar a região onde as lavouras se localizam, comparada a outras culturas, pois reflete mais a luz solar, com um índice maior de transpiração. Apesar de alguma compensação ambiental, Scott et al. (2011) ressaltam que a substituição da vegetação nativa pela plantação de cana provoca um aquecimento local.

Sobre as áreas de Cerrado desmatadas para incorporação do plantio de cana, entre os anos de 1995 e 2010, todos os municípios investigados apresentaram redução das áreas de remanescentes, na ordem de $19,6 \%$ ou 60.783 ha. Durante todo esse período, a maior redução de remanescentes ocorreu entre 2000 e 2005, com 9,74\%. Já o intervalo de menor redução foi entre 2005 e 2010 (3,67\%), período em que a expansão dos plantios se deu de forma menos intensa sobre áreas de Cerrado. Em termos percentuais, os municípios com maior redução das áreas de remanescentes foram Pompéu (23,11\%), Iguatama (22,28\%) e Bambuí (19,6\%).

\section{CONSIDERAÇÕES FINAIS}

Entre os anos de 1995 e 2010 ocorreram variações significativas no uso e ocupação do solo nos municípios localizados na região Centro-Oeste de Minas Gerais. Entre as principais mudanças, destaca-se um crescimento expressivo da área plantada de cana-de-açúcar, em especial nos municípios de Bambuí, Luz e Pompéu. As áreas de reflorestamento também tiveram uma expansão considerável, com destaque para Bambuí e Pompéu. Embora as lavouras de cana tenham ocupado, prioritariamente, áreas de pastagens e agricultura, no âmbito geral ocorreu um aumento da área agrícola nos municípios estudados. Por outro lado, houve também uma redução das áreas 
Diagnóstico do uso da terra na região Centro-Oeste de Minas Gerais, Brasil: a renovação da paisagem pela cana-de-açúcar e seus impactos socioambientais. Edmar Geraldo Oliveira, Manuel Eduardo Ferreira, Fernando Moreira de Araújo

de pastagem e de remanescentes de Cerrado, na ordem de $8 \%$ e $19 \%$, respectivamente.

As hipóteses iniciais desta pesquisa foram confirmadas, ao constatar-se que as mudanças no uso e ocupação do solo nos municípios investigados propiciaram uma transformação da dinâmica agrícola. Tal fenômeno deve-se especialmente à expansão canavieira, que tende a ocupar os melhores solos em razão de um maior nível de investimento.

Os resultados deste estudo indicaram que o avanço do setor sucroalcooleiro contribuiu para um crescimento do PIB nos municípios produtores de cana-de-açúcar, em especial naqueles onde as usinas estão instaladas. Sob o ponto de vista socioambiental, a expansão das lavouras canavieiras tem despertado diversas preocupações em relação à alteração da biodiversidade, perda de solos, disponibilidade hídrica e, segurança alimentar. Os dados deste estudo, obtidos por meio de imagens de satélite, confirmaram a redução de 60.783 ha de áreas remanescentes de Cerrado na região Centro-Oeste de Minas Gerais, no período entre 1995 e 2010. Por fim, destaca-se a necessidade de outras investigações complementares, com foco nos aspectos socioambientais, que permitam avaliar melhor as consequências desta nova dinâmica agrícola na região analisada.

\section{AGRADECIMENTOS}

A CAPES pela bolda de pesquisa concedida ao terceiro autor. Suporte financeiro para esta pesquisa também foi obtido junto ao United States National Aeronautics and Space Administration (NASA) - Land-Cover and Land-Use Change Program (LCLUC) (NNX11AE56G). Agradecemos também ao laboratório de Processamento de Imagens e Geoprocessamento (LAPIG), da UFG, pelo apoio técnico ao projeto, bem como ao Instituto Federal de Educação, Ciência e Tecnologia de Minas Gerais (IFMG) pelo apoio logístico na realização do trabalho.

\section{REFERÊNCIAS}

ÁVILA, S. R. S. A. Efeitos sócio econômicos da expansão da cana de açúcar no Vale do São Patrício. Dissertação de Mestrado - Universidade Federal de Brasília, 119 p, 2009.
BORGES, A.; FERREIRA, M. E.; PONTES, M. N.; Miziara, F.; RIBEIRO, F. L. Quantification of greenhouse gases emission from sugarcane burnings: a study case in savanna areas of Brazil. Revista Brasileira de Ciências Ambientais, v. 21, pp. 60-65, 2011.

CARRIJO, E. L.; MIZIARA, F. A Expansão do setor sucroalcooleiro como uma nova etapa da fronteira agrícola em Goiás: estudo de caso no município de Mineiros. Revista de Economia da UEG, Anápolis (GO), Vol. 05, nº 02, jul-dez., 2009.

CARRIJO, E. L. O. A expansão da fronteira agrícola no Estado de Goiás - setor sucroalcooleiro. UFG, Goiânia, GO. Dissertação de Mestrado, 2008.

CASTRO, S. S.; ABDALA, K.; SILVA, A. A.; BORGES, V. M. S. A expansão da cana-de-açúcar no cerrado e no estado de Goiás: elementos para uma análise espacial do processo. Boletim Goiano de Geografia, Goiânia, v. 30, n. 1, p. 171-191, jan./jun, 2010.

CASTRO, S. S.; BORGES, R. O.; SILVA, R. A. A.; BARBALHO, M. G. S. Estudo da expansão da cana-de-açúcar no Estado de Goiás: subsídios para uma avaliação do potencial de impactos ambientais. II Fórum de C\&T no Cerrado. Goiânia, GO, 2007.

FERREIRA, L. G.; FERREIRA, M. E.; ROCHA, G. F.; NEMAYER, M.; FERREIRA, N. C. Dinâmica agrícola e desmatamentos em áreas de cerrado: uma análise a partir de dados censitários e imagens de resolução moderada. Revista Brasileira de Cartografia, v. 61, n. 2, 2009.

FERREIRA, M. E.; FERREIRA, L. G.; MIZIARA, F.; SOARES-FILHO, B. S. Modeling landscape dynamics in the central Brazilian savanna biome: future scenarios and perspectives for conservation. Journal of Land Use Science, v. 7, 2012.

GIBBS, H. K.; JOHANSTON, M.; FOLEY, J. A.; ZAKS, D. Carbon payback times for crop-based biofuel expansion in the tropics: the effectos of changing yield and technology. Enviromental Research Letters, v. 3, 2008. DOI: 10.1088/1748-9326/3/3/034001. 
IBGE. 2004. Mapa de Biomas do Brasil. Escala 1:5.000.000. Disponível em: <http://mapas.ibge.gov. br/biomas2/viewer.htm> acesso em: 20 de out., 2007.

INPE-Instituto Nacional de Pesquisas Espaciais. Tutorial Spring: Spring básico. São José dos Campos: INPE, 2009. Disponível em: http://www.dpi.inpe.br/ spring/portugues/manuais.html.

MINAS GERAIS. Fundação João Pinheiro. Informativo CEI - PIB Minas Gerais - municípios e regiões -1999/2008. Disponível em: http://www.fjp.mg.gov. br/index.php/servicos/81-servicos-cei/58-produto-interno-bruto-de-minas-gerais. Acesso em 02 nov., 2011.

MIZIARA, F. Expansão da Lavoura de Cana em Goiás e Impactos Ambientais. In: XIV Congresso Brasileiro de Sociologia, 2009, Rio de Janeiro. Anais do XIV Congresso Brasileiro de Sociologia, v. 1, 2009.

Expansão de Fronteiras e Ocupação do Espaço no Cerrado: o caso de Goiás. In: Guimarães, Lorena D.; Silva, Maria Aparecida Daniel da; Anacleto, Teresa Cristina. (Org.). Natureza Viva Cerrado. $1^{a}$ ed. Goiânia: Editora da UCG, pp. 169-196, 2006.

MOREIRA, M. A. Fundamentos do sensoriamento remoto e metodologias de aplicação. 4. Ed. Atual. e ampl.- Viçosa- MG: Ed. UFV, 2011. 422 p.

PIRES, M. O. Cerrado: Sociedade e biodiversidade. In: IORIS, E (Org). Plantas Medicinais do Cerrado: perspectivas comunitárias para a saúde, o meio ambiente e o desenvolvimento sustentável. Mineiros/GO: Fundação Integrada Municipal de Ensino Superior: Projeto Centro Comunitário de Plantas Medicinais, pp. 155-173,1999.

RIBEIRO, N. V.; FERREIRA, L. G.; FERREIRA, N. C. Expansão da Cana-de-açúcar no Bioma Cerrado: Uma analise a partir da modelagem perceptiva de dados cartográficos e orbitais, Anais XIV Simpósio Brasileiro de Sensoriamento Remoto, 2009.

RUDORFF, B. F. T; SUGAWARA. L. M. Mapeamento da cana-de-açúcar na região centro-sul via imagens de satélites. Informe Agropecuário, Belo Horizonte, V. 28, n. 241, pp. 79-86, nov./dez., 2007.

ROSA, R. Introdução ao Sensoriamento Remoto. $5^{\mathrm{a}}$ ed., Uberlândia. Ed. Universidade Federal de Uberlândia, 2003.

ROVERE, E.L.L.; OBERLING, D.F.; OBERMAIER, M.; SOLARI, R.; WILLS, W. Avaliação da Sustentabilidade da Expansão do Etanol da Cana-de-açúcar no Brasil. Laboratório Interdisciplinar do Meio Ambiente (LIMA), Rio de Janeiro, 2009.

SANO, E. E.; ROSA, R.; BRITO, J. L. S.; FERREIRA, L. G. Mapeamento semidetalhado do uso da terra do Bioma Cerrado. Pesquisa Agropecuária Brasileira, Brasília, v. 43, n. 1, pp. 153-156, jan., 2008.

SANT'ANNA A.; FERRAZ, J.V.; SILVA, M.L.M et al. (Coord.). Agrianual 2009: Anuário da Agricultura Brasileira. São Paulo: IFNP, pp. 256-257, 2009.

SCOTT, R. L.; DAVID B. L.; GREGORY, P. A.; QIAOZHEN Mu; CHRISTOPHER B. Field. Direct impacts on local climate of sugar-cane expansion in Brazil. Nature Climate Change, v. 1, 2011.

SILVA, A. A.; MIZIARA, F. 2010. A expansão da fronteira agrícola e a localização das usinas de cana-de-açúcar. Pesquisa Agropecuária Tropical, UFG, Goiânia, v. 41, n. 3, pp. 399-407, jul./set., 2011.

SILVEIRA, L. J.; CARVALHO, N. D. Expansão do setor sucroalcooleiro no Brasil: algumas considerações. Revista Triangulo: Ensino Pesquisa Extensão, Uberaba-MG, v.1. n.1, pp. 81-95, jul./dez., 2008

SOUZA, E. L. de; MACEDO, I. de C. Etanol e bioeletricidade: a cana-de-açúcar no futuro da matriz energética. São Paulo: UNICA, 2009.

SOUZA, M. A. A dinâmica territorial da expansão do agronegócio sucroalcooleiro: contribuições teóricas para a atuação dos movimentos sociais. AGRÁRIA, São Paulo, n. 9, pp. 3-24, 2008. 